\title{
The Practical Guidelines for Physical Activity in Preventing Abnormal Body Weight in Asian Adolescents \\ Chia-Yu Yeh ${ }^{1}$, Ching-Hsing Chang ${ }^{2}$ and Chen-Kang Chang ${ }^{3, *}$ \\ ${ }^{1}$ Department of Economics, National Chi Nan University, 1 University Rd, Puli, Nantou County, 545 Taiwan \\ ${ }^{2}$ Department of BioBusiness Management, National Chiayi University, 580 Sinmin Rd, Chiayi City, 600 Taiwan \\ ${ }^{3}$ Department of Sport Performance, National Taiwan University of Sport. 16 Shuan-Shih Rd, Sec 2, Taichung, 404 Taiwan
}

\begin{abstract}
Background: Lack of physical activity is one of the major risk factors for obesity in adolescents. Before adopting the guidelines of the World Health Organization, The Ministry of Education in Taiwan recommended 210 minutes of moderate physical activity weekly for adolescents, equivalent to 840 METs$\mathrm{min} / \mathrm{wk}$. An additional $90 \mathrm{~min}$ of vigorous physical activity weekly is recommended for those who are more fit, equivalent to a total of $1560 \mathrm{METs}-\mathrm{min} / \mathrm{wk}$. The purpose of this study was to investigate the association between meeting the previous Taiwanese guidelines and the risk for being overweight, obese, and underweight, in adolescents.
\end{abstract}

Methods: The participants include 421 boys and 405 girls from middle schools. A multinomial logit model was adopted to simultaneously compare all weight categories.

Results: Meeting the level of $840 \mathrm{METs}-\mathrm{min} / \mathrm{wk}$ was associated with lower risks for obesity (odds ratio, OR $=0.41, \mathrm{p}<.1)$ and being underweight $(\mathrm{OR}=0.51, \mathrm{p}<.1)$ in boys, while meeting the level of 1560 METs$\mathrm{min} / \mathrm{wk}$ was associated a lower risk for obesity $(\mathrm{OR}=0.30, \mathrm{p}<.05)$ in girls.

Conclusions: The lower levels of physical activity can be a more practical, yet still effective, goal for policy implementation in Asian countries.

\section{Introduction}

Obesity in children and adolescents has become one of the major global health issues. The World Health Organization (WHO) estimated that 42 million children worldwide were overweight or obese in 2013 [1]. According to a recent national survey in Taiwan, $9.5 \%$ of the youth aged 13-17 years old are overweight, and another $6.9 \%$ are obese [2]. This prevalence is similar to that in many developed Western and Asian countries [3]. Lack of physical activity is one of the major risk factors for obesity in children and adolescents [4]. Childhood and adolescence are crucial periods for shaping an individual's lifestyle, such as being physically active. Not only can physical activity improve weight status, cardiometabolic and bone health, cognitive function, and reduce the risk of depression in youth [5], but its benefits can also be carried over to adulthood. Past studies showed that a higher level of physical activity in adolescence was associated with a higher level of physical activity in adulthood [6]. Youth who were regularly active also had fewer risk factors for cardiovascular diseases and diabetes later in life [5].

Although obesity has received the most attention in academic research and public policy, being underweight in adolescence is also an important health issue. Underweight adolescents are more susceptible to various physiological and psychological conditions such as bone loss [7] and psychiatric disorders [8]. The prevalence of adolescents being underweight ranges from $7.8 \%$ to $27.8 \%$ in developed Asian countries such as Taiwan, Japan, and South Korea [9].

The WHO recommends that children and adolescents aged 5-17 years should engage in 60 minutes or more of moderate- to vigorousintensity physical activity each day. As part of physical activity, the vigorous and muscle- and bone-strengthening physical activity should be included at least 3 times a week [10]. Many western countries have adopted the same guidelines. It has been shown that meeting these national physical activity guidelines could reduce the risk for obesity in adolescents in the US [11] and Europe [12]. Meeting the guidelines was also associated with better physical, psychological, social, and cognitive health indicators in children and adolescents [11]. Despite the tremendous efforts by governments, schools, and private sectors in many countries, $81 \%$ adolescents in the world failed to meet the WHO guidelines in 2016 [13].

Most $7^{\text {th }}-12^{\text {th }}$ graders in Taiwan spend more than 9 hours in schools on weekdays. Many of them also spend several hours attending after school classes on weekdays and weekends. With the limited time available for physical activity, adolescents in Taiwan have one of the lowest prevalence in the world in meeting the WHO guidelines $[14,15]$. Therefore, Taiwanese government established its own physical activity guidelines for children and adolescents with relatively modest goals. The Ministry of Education established Happy Living Project in 2007-2011, with the aim to accumulate 30 minutes of physical activity per day, equivalent to 210 minutes per week in 6- to 18 -year-old students. Starting from 2014, The Ministry of Education implemented Sports Health 150 (SH150) Project to encourage all schools to provide at least 150 minutes of physical activity per week in campus for all 6- to 18-year-old students, in addition to the regular physical education classes [16]. This regulation was incorporated into the National Sports Act in 2017. Before adopting the WHO guidelines in 2018, The Ministry of Education in Taiwan recommends that children and adolescents should engage in at least 210 minutes of moderate physical activity per week. An additional 90 minutes of vigorous physical activity per week is recommended for those who are

"Corresponding Author: Prof. Chen-Kang Chang, Department of Sport Performance, National Taiwan University of Sport. 16 Shuan-Shih Rd, Sec 2, Taichung, 404 Taiwan, Tel: +886-4-22213108 Ext 2235; Fax: +886-4-22232463; E-mail:wspahn@seed.net.tw

Citation: Yeh CY, Chang CH, Chang CK (2021) The Practical Guidelines for Physical Activity in Preventing Abnormal Body Weight in Asian Adolescents. Int J Clin Nutr Diet 7: 156. doi: https://doi.org/10.15344/2456-8171/2021/156

Copyright: (c) 2021 Yeh et al. This is an open-access article distributed under the terms of the Creative Commons Attribution License, which permits unrestricted use, distribution, and reproduction in any medium, provided the original author and source are credited. 
more fit. The Taiwanese guidelines were lower than those of the WHO and most of the Western countries, which recommend at least 420 minutes of physical activity per week.

Although meeting the WHO guidelines have been shown to be associated with numerous physiological and psychological benefit in children and adolescents, more than 4 out of 5 youth worldwide still do not reach that level of physical activity. Many efforts have been made at school, community, and family levels with limited long-term success in helping youth to meet the WHO guidelines. One has to wonder whether lower levels of physical activity, compared to the WHO guidelines, can still provide the similar effects on reaching healthy body weight in youth. The previous Taiwanese guidelines in children and adolescents may provide a basis for re-considering lower guidelines for physical activity. The purpose of this study was to investigate the association between meeting the previous Taiwanese physical activity guidelines and the risk for abnormal body weight, including the conditions of being overweight, obese, and underweight, in adolescents. A multinomial logit model [17] was adopted to simultaneously compare these 4 weight categories of underweight, normal, overweight, and obese.

\section{Materials \& Methods}

\section{Participants}

The survey for this study was performed in 17 public junior high schools in the metropolitan area of Taichung, Taiwan, during October 2011 and January 2012. There are 8 districts in the metropolitan area. One of the districts was not included in this study because it did not have a public junior high school. The number of total participants in each district was determined according to the distribution of adolescents in that area. Second, the number of classes to be sampled in each district was determined assuming that each class contained 30 students. Third, no more than 3 classes were sampled in each public junior high school, with 1 class in each grade. The sampled classes and schools were randomly selected. A total of 1165 questionnaires were collected. Among them, 826 questionnaires, representing 421 boys and 405 girls, with complete information were used for model analysis. This study protocol complies with the ethical guidelines of the Helsinki Declaration.

\section{Questionnaire design}

Information on the participants' physical activity in the 7 days prior to completing the survey was collected using the Taiwanese short version of the International Physical Activity Questionnaire [18]. Physical activities associated with physical education, housework, and part-time jobs were excluded. The total amount of physical activity was calculated by multiplying the time of each activity with the level of intensity, that is 8 METs for vigorous, 4 METs for moderate and 3.3 METs for light intensity [19]. According to the Taiwanese guidelines, the physical activity levels were categorized as below 840 (210 minutes $\mathrm{x} 4$ METs), 840-1560 (840 with an additional 90 minutes $\mathrm{x} 8 \mathrm{METs}$ ) and above $1560 \mathrm{METs}-\mathrm{min} / \mathrm{wk}$.

The purpose for engaging in physical activity included 4 options: maintaining a physically active lifestyle, seeking the accompaniment of family or friends, having fun, and spending free time. The participants could select as many options as they wished.

Self-reported height and body weight were collected to calculate BMI. Whether they were underweight, normal weight, overweight, or obese was determined based on the age-specific BMI criteria from Administration of Health Promotion, Taiwan [20]. It is noteworthy that the criteria are slightly different from the International Obesity Task Force reference [21]. Self-assessed health status and chronic diseases; parents' height, weight, and working status; combined household income; monthly allowance; and residence address were also collected.

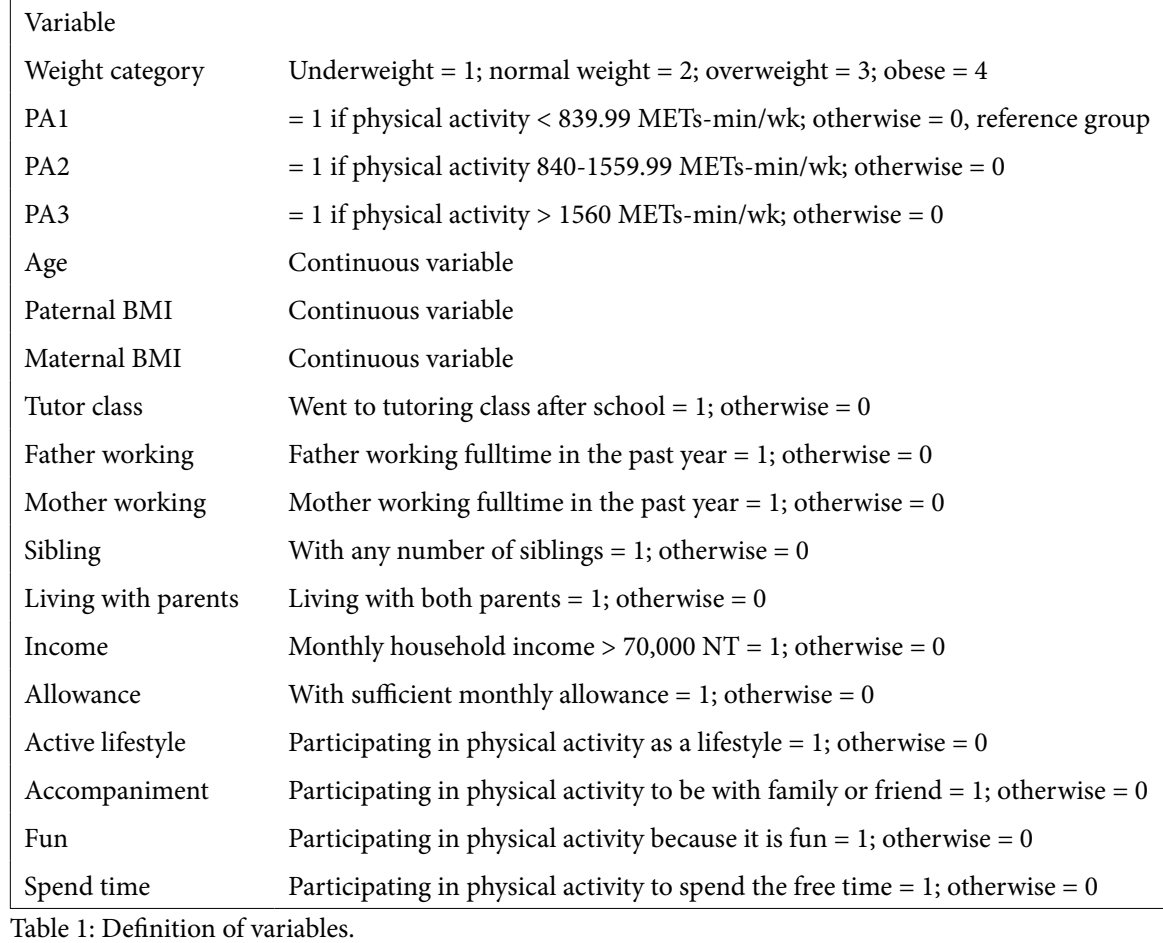




\section{Data analysis}

Table 1 shows the definitions of variables used in the multinomial logit model. Dependent variables were the conditions of being underweight, normal weight, overweight, and obese. A multinomial logit model [17] was adopted to simultaneously compare these 4 weight categories of underweight, normal, overweight, and obese. All statistical analyses were done using Stata Release 13 (College Station, TX, USA).

\section{Results}

Less than half (46.9\%) of the boys and $60.3 \%$ of the girls reported normal body weight. There were $29.5 \%$ boys and $15.5 \%$ girls were obese or overweight, while approximately 1 in 5 boys and girls reported being underweight (Table 2). The self-reported total amount of physical activity showed great variations among the participants. Approximately one-third of the boys and half of the girls failed to meet the physical activity guidelines of Taiwan (Table 3 ).

\begin{tabular}{|lllllllc|}
\hline & \multicolumn{3}{c}{ All } & \multicolumn{2}{c}{ Boys } & \multicolumn{2}{c|}{ Girls } \\
& $\mathrm{N}$ & $\%$ & $\mathrm{~N}$ & $\%$ & $\mathrm{~N}$ & $\%$ \\
Underweight & 243 & 20.9 & 120 & 20.1 & 123 & 21.7 \\
Normal weight & 622 & 53.4 & 280 & 46.9 & 342 & 60.3 \\
Overweight & 142 & 12.2 & 93 & 15.6 & 49 & 8.6 \\
Obesity & 122 & 10.5 & 83 & 13.9 & 39 & 6.9 \\
Missing value & 36 & 3.1 & 21 & 3.5 & 14 & 2.5 \\
Total & 1,165 & 100 & 597 & 100 & 567 & 100 \\
\hline
\end{tabular}

Table 2: The number and percentage of participants in each weight category.
For boys who reported physical activity levels of 840-1560 METs$\mathrm{min} / \mathrm{wk}$, the risk for obesity and being underweight was significantly lower than those reporting lower or higher levels of weekly physical activity (Table 4). However, self-reported physical activity exceeding $1560 \mathrm{METs}-\mathrm{min} / \mathrm{wk}$ was not correlated with the abnormal body weight. Paternal BMI was positively associated with a higher risk for obesity, while the BMI of both parents was negatively associated with the risk for being underweight.

In girls, a physical activity level exceeding 1560 METs-min/wk was associated with a lower risk of obesity (Table 4). Participating in physical activity with the aim of maintaining an active lifestyle also was also negatively associated the risk of obesity. Physical activity levels had no effect on the risk of being underweight or overweight. Maternal BMI was positively correlated with girls' risk of obesity, while parental BMI was positively correlated with the risk of being overweight. Similar to boys, the BMI of both parents was negatively associated with the risk of being underweight. The father's working full-time had a negative association with the risk of obesity in girls, while the mother's working full-time had a positive association. Low household income was also positively associated with the risk for obesity in girls. When all participants were pooled together, meeting or exceeding the physical activity guidelines of $840 \mathrm{METs}-\mathrm{min} / \mathrm{wk}$ was correlated with a lower risk of obesity (Table 5).

Table 6 shows the odds ratios for being underweight, overweight, and obese in boys and girls. Meeting the recommended physical activity level of 840-1560 METs-min/wk was associated with statistically important reductions in the risk for obesity by $59 \%$ and the risk for being underweight by $49 \%$ in boys, but the effect was not statistically significant for girls. Only a self-reported physical activity

\begin{tabular}{|c|c|c|c|c|c|c|}
\hline \multirow[t]{2}{*}{ Variables } & \multicolumn{2}{|c|}{ All } & \multicolumn{2}{|c|}{ Boys } & \multicolumn{2}{|c|}{ Girls } \\
\hline & Mean & $\mathrm{SD}$ & Mean & $\mathrm{SD}$ & Mean & SD \\
\hline PA (METs-minutes/week) & 1981.6 & 2934.4 & 2415.4 & 3492.2 & 1524.0 & 2106.3 \\
\hline $\mathrm{PA}^{\mathrm{a}}$ & 0.43 & 0.50 & 0.35 & 0.48 & 0.52 & 0.50 \\
\hline $\mathrm{PA} 2^{\mathrm{b}}$ & 0.19 & 0.39 & 0.18 & 0.39 & 0.20 & 0.40 \\
\hline $\mathrm{PA}^{\mathrm{c}}$ & 0.37 & 0.48 & 0.47 & 0.50 & 0.28 & 0.45 \\
\hline Age & 13.34 & 0.95 & 13.34 & 0.94 & 13.33 & 0.96 \\
\hline Paternal BMI & 24.30 & 9.98 & 24.56 & 13.53 & 24.04 & 3.56 \\
\hline Maternal BMI & 21.87 & 3.61 & 21.89 & 3.62 & 21.84 & 3.61 \\
\hline Tutor class & 0.62 & 0.49 & 0.60 & 0.49 & 0.63 & 0.48 \\
\hline Father working & 0.90 & 0.31 & 0.88 & 0.32 & 0.91 & 0.28 \\
\hline Mother working & 0.71 & 0.46 & 0.68 & 0.47 & 0.72 & 0.45 \\
\hline Siblings & 0.90 & 0.30 & 0.89 & 0.31 & 0.90 & 0.29 \\
\hline Living with parents & 0.88 & 0.33 & 0.87 & 0.33 & 0.88 & 0.33 \\
\hline Income & 0.21 & 0.41 & 0.21 & 0.40 & 0.20 & 0.40 \\
\hline Allowance & 0.70 & 0.46 & 0.67 & 0.47 & 0.73 & 0.44 \\
\hline \multicolumn{7}{|l|}{ Reasons for PA } \\
\hline Active lifestyle & 0.29 & 0.45 & 0.34 & 0.47 & 0.23 & 0.42 \\
\hline Accompaniment & 0.33 & 0.47 & 0.31 & 0.47 & 0.34 & 0.48 \\
\hline Fun & 0.61 & 0.49 & 0.73 & 0.44 & 0.55 & 0.50 \\
\hline Spend time & 0.44 & 0.50 & 0.49 & 0.50 & 0.39 & 0.49 \\
\hline $\mathrm{N}$ & \multicolumn{2}{|c|}{1165} & \multicolumn{2}{|c|}{597} & \multicolumn{2}{|c|}{567} \\
\hline
\end{tabular}




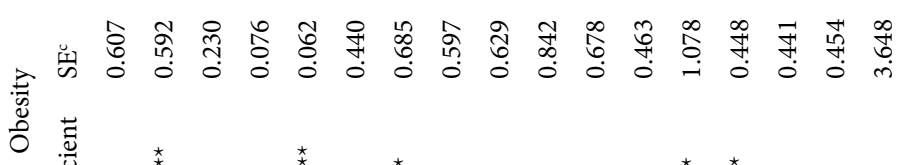

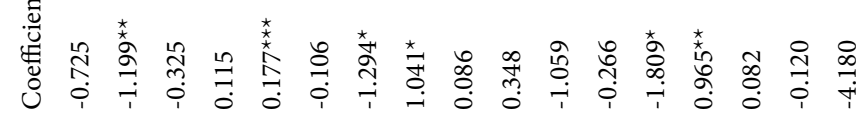

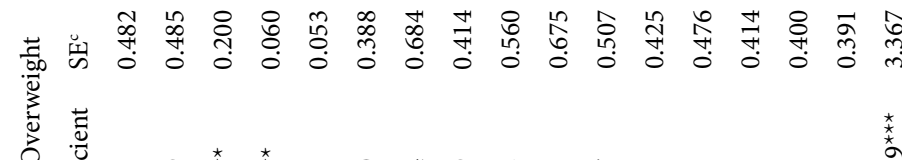
혛

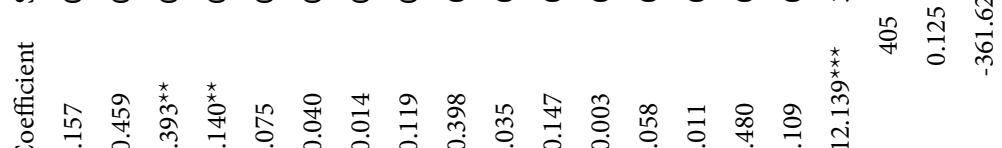

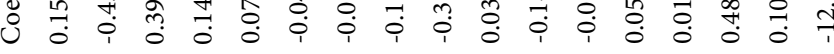

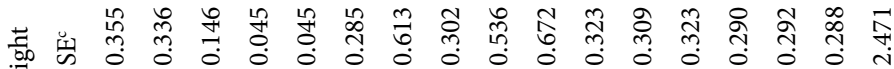
要 है

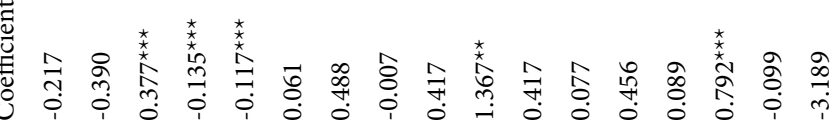

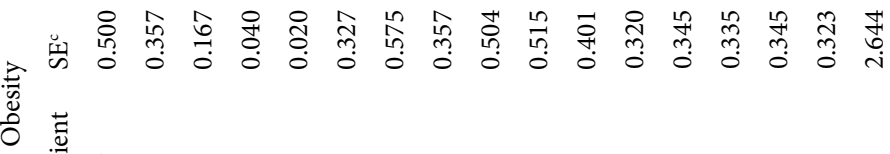

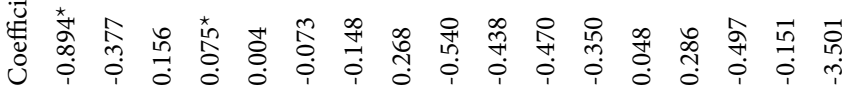

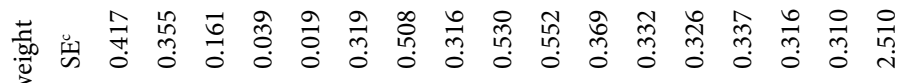
ติ

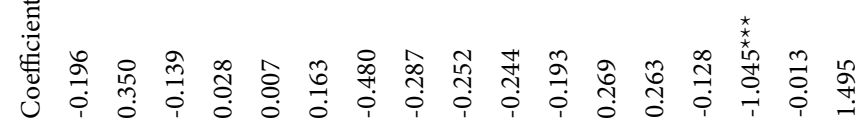

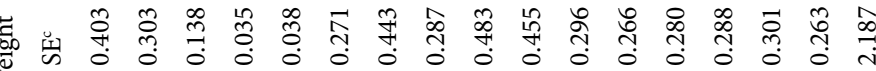
苋

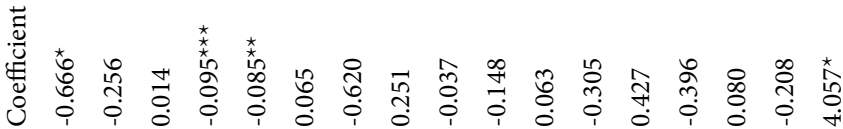


Citation: Yeh CY, Chang CH, Chang CK (2021) The Practical Guidelines for Physical Activity in Preventing Abnormal Body Weight in Asian Adolescents. Int J Clin Nutr Diet 7: 156. doi: https://doi.org/10.15344/2456-8171/2021/156

\begin{tabular}{|c|c|c|c|c|c|c|}
\hline \multirow[t]{2}{*}{ Variables } & \multicolumn{2}{|c|}{ Underweight } & \multicolumn{2}{|c|}{ Overweight } & \multicolumn{2}{|c|}{ Obesity } \\
\hline & Coefficient & $\mathrm{SE}^{\mathrm{c}}$ & Coefficient & $\mathrm{SE}^{\mathrm{c}}$ & Coefficient & $\mathrm{SE}^{\mathrm{c}}$ \\
\hline $\mathrm{PA} 2^{\mathrm{a}}$ & -0.410 & 0.260 & -0.098 & 0.306 & $-0.818^{\star *}$ & 0.376 \\
\hline $\mathrm{PA}^{\mathrm{b}}$ & -0.280 & 0.218 & -0.392 & 0.277 & $-0.530^{*}$ & 0.283 \\
\hline Age & $0.172^{\star}$ & 0.097 & 0.059 & 0.121 & 0.043 & 0.129 \\
\hline Paternal BMI & $-0.106^{* * *}$ & 0.027 & $0.064^{\star *}$ & 0.032 & $0.095^{\star * *}$ & 0.034 \\
\hline Maternal BMI & $-0.102^{* * *}$ & 0.029 & 0.018 & 0.020 & 0.019 & 0.019 \\
\hline Tutor class & 0.066 & 0.191 & 0.075 & 0.240 & -0.150 & 0.253 \\
\hline Father working & -0.256 & 0.335 & -0.348 & 0.388 & -0.305 & 0.422 \\
\hline Mother working & 0.147 & 0.203 & -0.230 & 0.243 & $0.492^{*}$ & 0.296 \\
\hline Siblings & 0.220 & 0.344 & -0.340 & 0.372 & -0.377 & 0.378 \\
\hline Living with parents & 0.484 & 0.351 & -0.033 & 0.408 & -0.114 & 0.412 \\
\hline Income & 0.209 & 0.212 & -0.226 & 0.289 & $-0.557^{\star}$ & 0.333 \\
\hline Allowance & -0.111 & 0.197 & 0.255 & 0.257 & -0.258 & 0.255 \\
\hline Active lifestyle & $0.394^{*}$ & 0.207 & 0.159 & 0.261 & -0.309 & 0.304 \\
\hline Accompaniment & -0.121 & 0.200 & 0.003 & 0.255 & $0.507^{\star *}$ & 0.258 \\
\hline Fun & $0.469^{* *}$ & 0.204 & $-0.447^{\star}$ & 0.243 & -0.191 & 0.263 \\
\hline Spend time & -0.173 & 0.189 & 0.064 & 0.237 & -0.107 & 0.254 \\
\hline Gender & 0.215 & 0.191 & $0.956^{\star * *}$ & 0.244 & $1.020^{* * *}$ & 0.265 \\
\hline Intercept & 0.673 & 1.590 & $-3.845^{\star *}$ & 1.918 & $-4.459^{* *}$ & 2.053 \\
\hline $\mathrm{N}$ & & & & 26 & & \\
\hline Pseudo $\mathrm{R}^{2}$ & & & & 71 & & \\
\hline Log likelihood & & & & 0.91 & & \\
\hline
\end{tabular}

\begin{tabular}{|c|c|c|c|c|c|c|c|c|c|}
\hline \multirow[t]{2}{*}{ Variables } & \multicolumn{3}{|c|}{ All } & \multicolumn{3}{|c|}{ Boys } & \multicolumn{3}{|c|}{ Girls } \\
\hline & underweight & overweight & obesity & underweight & overweight & obesity & underweight & overweight & obesity \\
\hline $\mathrm{PA} 2^{\mathrm{a}}$ & 0.66 & 0.91 & $0.44^{\star *}$ & $0.51^{*}$ & 0.82 & $0.41^{\star}$ & 0.81 & 1.17 & 0.48 \\
\hline $\mathrm{PA}^{\mathrm{b}}$ & 0.76 & 0.68 & $0.59^{*}$ & 0.77 & 0.70 & 0.69 & 0.68 & 0.63 & $0.30^{* *}$ \\
\hline Age & $1.19^{*}$ & 1.07 & 1.04 & 1.01 & 0.87 & 1.17 & $1.46^{* * *}$ & $1.48^{* *}$ & 0.72 \\
\hline Paternal BMI & $0.90^{* * *}$ & $1.07^{\star *}$ & $1.11^{\star * *}$ & $0.91^{\star * *}$ & 1.03 & 1.08 & $0.87^{\star * *}$ & $1.15^{\star *}$ & 1.12 \\
\hline Maternal BMI & $0.90^{* * *}$ & 1.02 & 1.02 & $0.92^{\star *}$ & 1.01 & 1.00 & $0.89^{\star * *}$ & 1.08 & $1.19^{* * *}$ \\
\hline Tutor class & 1.07 & 1.08 & 0.86 & 1.07 & 1.18 & 0.93 & 1.06 & 0.96 & 0.90 \\
\hline Father working & 0.77 & 0.71 & 0.74 & 0.54 & 0.62 & 0.86 & 1.63 & 0.96 & $0.27^{\star}$ \\
\hline Mother working & 1.16 & 0.79 & 1.63 & 1.28 & 0.75 & 1.31 & 0.99 & 0.89 & $2.83^{*}$ \\
\hline Siblings & 1.25 & 0.71 & 0.69 & 0.96 & 0.78 & 0.58 & 1.52 & 0.67 & 1.09 \\
\hline Living with parents & 1.63 & 0.97 & 0.89 & 0.86 & 0.78 & 0.65 & $3.92^{\star *}$ & 1.04 & 1.42 \\
\hline Income & 1.23 & 0.80 & 0.57 & 1.06 & 0.82 & 0.63 & 1.52 & 0.86 & 0.35 \\
\hline Allowance & 0.89 & 1.29 & 0.77 & 0.74 & 1.31 & 0.71 & 1.08 & 1.00 & 0.77 \\
\hline Active lifestyle & 1.48 & 1.17 & 0.73 & 1.53 & 1.30 & 1.05 & 1.58 & 1.06 & $0.16^{*}$ \\
\hline Accompaniment & 0.89 & 1.00 & $1.66^{* *}$ & 0.67 & 0.88 & 1.33 & 1.09 & 1.01 & $2.62^{* *}$ \\
\hline Fun & 1.60 & $0.64^{\star}$ & 0.83 & 1.08 & $0.35^{\star * *}$ & 0.61 & $2.21^{\star * *}$ & 1.62 & 1.09 \\
\hline Spend time & 0.84 & 1.07 & 0.90 & 0.81 & 0.99 & 0.86 & 0.91 & 1.11 & 0.89 \\
\hline Gender & 1.24 & $2.60^{* * *}$ & $2.77^{* * *}$ & & & & & & \\
\hline $\mathrm{N}$ & & 826 & & & 421 & & & 405 & \\
\hline
\end{tabular}


level of more than 1560 METs-min/wk appeared to associate with a lower risk for obesity by $70 \%$ in girls. The most effective variable in girls was to maintain an active lifestyle, with an odds ratio of 2.62 .

\section{Discussion}

The results of this study indicated that 210 minutes of moderate physical activity per week, or $840 \mathrm{METs}$-min/wk, are associated with a lower risk for obesity and being underweight in boys. However, an additional 90-minute of vigorous physical activity per week, or a total of $1560 \mathrm{METs}-\mathrm{min} / \mathrm{wk}$, is associated with a lower risk for obesity in girls. The curriculum in most developed countries requires 2 to 3 physical educations class, a total of 90-135 minutes, each week. A metaanalysis revealed that students spent approximately $40-50 \%$ of the time in physical education classes engaging in moderate-to-vigorous activity [22]. Ideally, most adolescents could meet the guidelines of 210 minutes in schools by engaging in physical education and 150 minutes of physical activities outside regular classes.

It has been suggested that at least 46 minutes of moderate and 14 minutes of vigorous activity per day are required to reduce the risk for being overweight, while the same amount of moderate and 10 minutes of vigorous physical activity per day are required to reduce the risk for obesity [23]. Another study suggested that at least 67 minutes of moderate-to-vigorous physical activity daily are required for reducing the risk for being overweight and obese in boys, and 57 minutes for girls [24]. These cutoff levels are very close to the guidelines of 60 minutes of moderate-to-vigorous physical activity per day issued by North American and European countries. However, this study indicated that a lower level of physical activity is still sufficient for reducing the risk for obesity and being underweight in boys. With the global difficulty in meeting the WHO guidelines [13], the lower guidelines may provide a more practical, yet still effective, goal for policy implementation.

The gender differences in the effect of physical activity and weight categories in this study were also reported elsewhere $[25,26]$. Generally, boys tended to be at higher risk for being overweight and obese, to have a higher level of physical activity, and to have unhealthier diet behaviors than girls. The differences were the results of complicated biological, social, and cultural factors [27]. The higher physical activity level that was related to a lower risk for obesity in girls may be impractical in intervention programs as only $28 \%$ of the girls in this study met that level. Our results showed that engaging in exercise with the aim of maintaining a physically active lifestyle, after controlling for the physical activity level, is associated with a lower risk for obesity by $83.6 \%$ in girls. Therefore, it may be more effective to emphasize an active lifestyle rather than the total amount of physical activity in girls in order to prevent obesity.

In addition to physical activity, many factors such as diet, sedentary behavior, and sleep, also contribute to the development of obesity and health [11]. Among these intercorrelated factors, high physical activity was the most consistently associated with desirable physiological and psychological health indicators in youth [28]. The Youth Risk Behavior Surveillance Survey also revealed that physical inactivity led to increased odds of being obese in boys and girls, regardless of TV time and sleep duration [29].

Another interesting finding is that having a physical activity level above $840 \mathrm{METs}-\mathrm{min} / \mathrm{wk}$ is strongly associated with a reduction in the risk for being underweight in boys by almost $50 \%$ (odds ratio $=0.51$ ).
It is possible that sufficient physical activity can build more muscles and increase the appetite in adolescent boys. Another possibility is that boys who engage in sufficient physical activity have a healthier body image of themselves and would not focus on excessive thinness [30].

This study has several limitations. First, body weight and height were self-reported by the participants. Despite the possibility of underreporting, self-reported heights and weights still provide extremely reliable classification of weight status while saving time and money in large-scale data collections. Second, body image was not investigated but could be an important factor for being underweight, especially in adolescent girls. Third, the information on height and body weight of the parents and household income provided by the participants may not be reliable. The physical activity levels of parents, reported by the parents themselves or measured objectively, could also be included in future models. Lastly, due to the cross-sectional study design, our findings do not provide a causal interpretation on the relationship between physical activity and the risk for unhealthy weight status.

\section{Conclusions}

Our results showed that 210 minutes of moderate physical activity per week was associated with a lower risk for obesity and being underweight in boys. On the other hand, emphasizing the importance of a physically active lifestyle may be more effective in preventing obesity in girls. Although it has been suggested that at least 420 minutes of moderate-to-vigorous physical activity per week are required to reduce the risk for being overweight and obese in western countries, this study provides the evidence for a more practical, yet still effective, goal for policy implementation in the Asian region. Such guidelines may be more applicable in high-income Asia-Pacific countries where the current physical activity levels in children and adolescents are among the lowest in the world [13].

\section{Competing Interests}

The authors declare that they have no competing interest.

\section{References}

1. World Health Organization (2015) Interim Report of the Commission on Ending Childhood Obesity.

2. National Health Research Institute (2011) Nutrition and Health Survey in Taiwan 2010: Junior high school students.

3. Janssen I, Katzmarzyk PT, Boyce WF, Vereecken C, Mulvihill C, et al. (2005) Comparison of overweight and obesity prevalence in school-aged youth from 34 countries and their relationships with physical activity and dietary patterns. Obes Rev 6: 123-132.

4. Katzmarzyk PT, Barreira TV, Broyles ST, Champagne CM, Chaput JP, et al. (2015) Physical activity, sedentary time, and obesity in an international sample of children. Med Sci Sports Exerc 47: 2062-2069.

5. Piercy KL, Troiano RP, Ballard RM, Carlson SA, Fulton JE, et al. (2018) The physical activity guidelines for Americans. JAMA 320: 2020-2028.

6. Belanger M, Sabiston CM, Barnett TA, O'Loughlin E, Ward S, et al. (2015) Number of years of participation in some, but not all, types of physical activity during adolescence predicts level of physical activity in adulthood: Results from a 13-year study. Int J Behav Nutr Phys Act 12: 76.

7. Bialo SR, Gordon CM (2014) Underweight, overweight, and pediatric bone fragility: impact and management. Curr Osteoporos Rep 12: 319-328.

8. Henninghausen $K$, Rischmuller $B$, Heseker $H$, Remschmidt $H$, Hebebrand J, et al. (1999) Low body mass indices in adolescents with obsessivecompulsive disorder. Acta Psychiatr Scand 99: 267-273. 
Citation: Yeh CY, Chang CH, Chang CK (2021) The Practical Guidelines for Physical Activity in Preventing Abnormal Body Weight in Asian Adolescents. Int J Clin Nutr Diet 7: 156. doi: https://doi.org/10.15344/2456-8171/2021/156

9. Mak KK, Tan SH (2012) Underweight problems in Asian children and adolescents. Eur J Pediatr 171: 779-785.

10. World Health Organization (2010) Global recommendations on physical activity for health.

11. Kracht CL, Champagne CM, Hsia DS, Martin CK, Newton RL Jr, et al. (2020) Association between meeting physical activity, sleep, and dietary guidelines and cardiometabolic risk factors and adiposity in adolescents. J Adolesc Health 66: 733-739.

12. Martinez-Gomez D, Ruiz JR, Ortega FB, Veiga OL, Moliner-Urdiales D, et al. (2010) Recommended levels of physical activity to avoid an excess of body fat in European adolescents: the HELENA Study. Am J Prev Med 39: 203-211.

13. Guthold R, Stevens GA, Riley LM, Bull FC (2020) Global trends in insufficient physical activity among adolescents: a pooled analysis of 298 populationbased surveys with 1.6 million participants. Lancet Child Adolesce Health 4: 23-35.

14. Aubert S, Barnes JD, Abdeta C, Abi Nader P, Adeniyi AF, et al. (2018) Global Matrix 3.0 Physical Activity Report Card grades for children and youth results and analysis from 49 countries. J Phys Act Health 15: S251-S273.

15. Wu CL, Chang CK (2019) Results from the Chinese Taipei (Taiwan) 2018 Report Card on physical activity for children and youth. J Exerc Sci Fit 17: 8-13.

16. Sports Administration, Ministry of Education (2015) Sports Health 150 .

17. Bodea TD, Garrow LA, Meyer MD, Ross CL (2009) Socio-demographic and built environment influences on the odds of being overweight or obese: The Atlanta experience. Transport Res Part A Pol Pract 43: 430-444.

18. Liou YM, Jwo CJ, Yao KG, Chiang LC, Huang LH, et al. (2008) Selection of appropriate Chinese terms to represent intensity and types of physical activity terms for use in the Taiwan version of IPAQ. J Nurs Res 16: 252-263.

19. Craig CL, Marshall AL, Sjostrom M, Bauman AE, Booth ML, et al. (2003) International Physical Activity Questionnaire (IPAQ): 12-country reliability and validity. Med Sci Sport Exerc 35: 1381-1395.

20. Health Promotion Adminstration (2018) Definition of underweight, normal weight, overweight, and obesity in children and adolescents.

21. Cole TJ, Bellizzi MC, Flegal KM, Dietz WH (2000) Establishing a standard definition for child overweight and obesity worldwide: international survey. BMJ 320: 1240-1243.

22. Hollis JL, Sutherland R, Williams AJ, Campbell E, Nathan N, et al. (2017) A systematic review and meta-analysis of moderate-to-vigorous physical activity levels in secondary school physical education lessons. Int J Behav Nutr Phys Act 14: 52

23. Latt E, Maestu J, Ortega FB, Raask T, Jurimae T, et al. (2015) Vigorous physical activity rather than sedentary behaviour predicts overweight and obesity in pubertal boys: a 2-year follow-up study. Scand J Public Health 43: $276-282$.

24. Laguna M, Ruiz JR, Lara MT, Aznar S (2013) Recommended levels of physical activity to avoid adiposity in Spanish children. Pediatr Obes 8: 62-69.

25. Menon S, Philipneri A, Ratnasingham S, Manson H (2019) The integrated role of multiple healthy weight behaviours on overweight and obesity among adolescents: a cross-sectional study. BMC Public Health 19: 1157.

26. Zhu $X$, Haegele JA, Tang $Y$, Wu X (2018) Prevalence and demographic correlates of overweight, physical activity, and screen time among schoolaged children in urban China: The Shanghai Study. Asia Pac J Public Health 30: $118-127$.

27. Sweeting HN (2008) Gendered dimensions of obesity in childhood and adolescence. Nutr I 7:1.

28. Saunders TJ, Gray CE, Poitras VJ, Chaput JP, Janssen I, et al. (2016) Combinations of physical activity, sedentary behaviour and sleep: relationships with health indicators in school-aged children and youth. Appl Physiol Nutr Metab 41: 283-293.

29. Laurson KR, Lee JA, Eisenmann JC. (2015) The cumulative impact of physical activity, sleep duration, and television time on adolescent obesity: 2011 Youth Risk Behavior Survey. J Phys Act Health 12: 355-360.

30. Kopcakova J, Veselska ZD, Geckova AM, van Dijk JP, Reijneveld SA, et al. (2014) Is being a boy and feeling fat a barrier for physical activity? The association between body image, gender and physical activity among adolescents. Int J Environ Res Public 11: 11167-11176. 